\title{
PENGARUH ATRIBUT SUPERMARKET TERHADAP IMPULSE BUYING (SURVEI PADA SUPERMARKET DI KOTA BANDUNG)
}

\author{
Ria Arifianti \\ (Dosen Administrasi Niaga FISIP UNPAD)
}

\begin{abstract}
This research is conducted to analyze the influence of attribute supermarket on impulse buying at Supermarket Bandung. The Goal of this research is also to know the attribute supermarket that influence the impulse buying , supporting factors and how the problems take place.

The descriptive-verificative method is used in this research. Data collection methods are literature and field studies. Field study covers observation, interview and structural questionnaires. The questionnaires are given to 75 consumers at Supermarket Bandung. The sistematic sampling is used as sampling tecgnique. Data are analyzed by qualitative analysis and correlation multiple regresion statistical.

The analysis confirms that there are influences on attribute supermarket, impulse buying at Supermarket Bandung. That is, if attribute supermarket is carefully done, it will increase the impulse buying.
\end{abstract}

Key words : Attribute supermarket, impulse buying

\section{PENDAHULUAN}

Bisnis ritel merupakan keseluruhan aktivitas penjualan barang atau jasa secara langsung kepada konsumen yang digunakan untuk memenuhi kebutuhan hidupnya. Untuk dapat memenuhi hal tersebut dibutuhkan suatu teknologi yang tinggi. Teknologi tinggi ini memudahkan pelayanan, pemrosesan, serta pengantaran layanan yang lebih cepat, teliti dan memuaskan dan melayani pelanggan.

Salah satu bentuk ritel adalah Supermarket. Pada 2008 omzet supermarket adalah $26,2 \%$ dari total omzet seluruh pasar modern di Indonesia. Sementara minimarket $32,1 \%$ dan hypermarket $41,7 \%$. (http : // www. indef.or.id/xpload /upload/pubs/exum hypermarket, 2010)

Keadaan ini mendorong persaingan dunia bisnis khususnya supermarket. Mereka berusaha untuk dapat menarik konsumen agar dapat tetap bertahan di tengah persaingan. Hal ini terjadi karena supermarket perkembangannya semakin menurun, selain itu masyarakat perkotaan menyukai berbelanja di toko modern dibandingkan pasar tradisional.

Keadaan ini membuat para pengusaha mencari cara agar dapat memenangkan persaingan dan menarik konsumen semakin banyak. Salah satunya adalah menggunakan strategi roda eceran. Strategi ini menitikberatkan pada pengembangan suatu toko dengan menyediakan barang yang lengkap, pelayanan yang baik disertai strategi harga.

Salah satu bentuk strategi roda eceran adalah strategi harga naik turun (high-low), dimana harga barang di toko diatur sedemikian rupa sehingga berfluktuasi antara harga normal dan harga diskon, seperti harga yang kian murah, pelayanan barang, pelayanan yang paling baik, lokasi yang strategis. Keadaan ini dapat mengakibatkan terjadinya permainan harga antar pengusaha ritel (Nurudin Abdullah, Bisnis Indonesia, 2003)

Di sisi lain timbulnya pengecer besar seperti supermarket secara sosial mampu memberikan dampak positif bagi pemerintah khususnya kota Bandung terutama di dalam menyerap tenaga kerja yaitu sekitar 17 juta orang (18\%) bekerja di sektor ritel, laju pertumbuhan ekonomi, serta meningkatkan pendapatan daerah yaitu sekitar 86 \% atau pada ttahun 2006 15.324.063,00 17.980.390,60 21.782.689,08 (Bandung dalam angka, 2009 : 73). Oleh karena itu Pemerintah daerah menggunakan instrumen pajak/retribusi yang menghasilkan Pendapatan Asli Daerah (PAD) dalam mengkompensasi kecepatan perkembangan ritel modern khususnya supermarket.

Sedangkan dari sudut produsen dan perusahaan adalah meningkatkan kapasitas pemasaran para distributornya dan pelaku terkait, tetapi pada sisi persaingan usaha memberikan 
dampak negatif bagi pengecer kecil. Karena hal tersebut, maka pasar modern menjadi berkembang pesat. Hal ini dapat digambarkan sebagai berikut :

Pesatnya perkembangan ritel modern ini berdampak pada perilaku manusia. Pada saat ini dalam perilaku manusia telah terjadi pergeseran perilaku (perubahan perilaku). Perilaku orang yang berbelanja dengan terencana menjadi tidak terencana. Orang yang tidak terencana berfikir pendek dan mencari yang serba instan dan mencari produk yang bisa memberi keuntungan jangka pendek untuk menyelesaikan masalah yang ada di depan mata saja. Salah satu indikasi besarnya konsumen yang punya pikiran jangka pendek adalah maraknya kredit konsumsi yang didorong oleh perhitungan kebutuhan jangka pendek, yaitu mendapatkan barang dengan cara cepat. Penurunan daya beli membuat konsumen harus berfikir untuk mencari solusi dalam jangka pendek dulu.

Keadaan ini melibatkan faktor emosi dalam pengambilan keputusannya, Mereka dituntut untuk memenuhi kebutuhan hidupnya dengan segera. Emosi dapat menjadi dasar dari pembelian yang dominan. Hal ini mendorong konsumen bertindak karena daya tarik atas sentimen atau gairah tertentu. Ini berarti terjadinya impulse buying yaitu suatu perilaku orang yang tidak merencanakan sesuatu dalam belanja. Konsumen yang melakukan impulse buying tidak berfikir untuk membeli produk atau merek tertentu. Mereka langsung melakukan pembelian karena ketertarikan pada merek atau produk saat itu atau sedikit membutuhkan pertimbangan atau informasi yang lengkap dalam melakukan keputusan membeli. Selain itu biasanya para konsumen tidak membawa daftar barang-barang yang harus dibeli (Yongki Susilo, 2007 : 15)

Dorongan dalam impulse merupakan hal penting dan mempunyai point tersendiri untuk individual. Berdasarkan studi penelitian dikatakan bahwa kegiatan impulse buying memang banyak dilakukan orang, sekitar $50 \%$ yang dihabiskan konsumen di dalam toko (Dittmar, Beattie and Friese 1995, dalam Tremblay, 2005 : 4). Kegiatan impulse buying di kota-kota besar di Indonesia disinyalir sekitar $35-41 \%$ pada hari kerja dan pada hari Sabtu dan Minggu jumlah tersebut meningkat menjadi $61 \%$. (Yadi Budhi Setiawan, Marketing, 2007: 86).
Perilaku impulse buying adalah peluang bagi peritel untuk memperkenalkan produk-produk baru.. Impulse buying terjadi pada konsumen apabila pertama produk yang memiliki harga yang rendah, kedua produk-produk yang memiliki mass marketing, sehingga ketika berbelanja konsumen ingat bahwa produk tersebut tersebar pernah diiklankan di televisi. Ketiga adalah produk-produk dalam ukuran kecil dan mudah disimpan. Biasanya konsumen mengambil produk ini karena dianggap murah dan tidak terlalu membebani keranjang atau kereta belanjanya. Stern (1962, dalam Evans, jamal, Foxall, 2006 : 88)

Kecenderungan impulse buying merupakan trend prilaku pembelian yang marak di Supermarket/Hipermarket (Bayley and Nancarrow, 1998 : 99) Keadaan ini menjadi suatu kebiasaan yang rutin di masyarakat. Hal ini mendorong perubahan prilaku seseorang. Tuntutan kebutuhan yang cepat mengakibatkan tingkat prilaku seseorang meningkat dan cenderung merangsang psikologi seseorang menjadi negatif seperti perubahan watak/sifat seseorang atau inginnya mendapat penghormatan dari orang lain. (Silvera, Lavacl, Kropp. 2008 : 23-24, Verplanken, Herabadi, Perry, dan Silvera, 2005 : , Tafarodi and Swann, 1995 : 47-48, Huelsman, Nemarick, Munz, $1998:$ :54-55).

Keadaan ini terlihat pada situasi supermarket yang menyediakan barang yang dapat memenuhi kebutuhan mereka (konsumen) dan memberikan keuntungan bagi mereka secara finansial. Mereka lupa dengan tujuan ketika mereka masuk ke toko tersebut. Hal ini akan mengakibatkan terjadinya impulse buying. Faktor lain yang mengakibatkan impulse buying apabila gerai sedang melakukan aktifitas visual merchandising yang menarik minat untuk cobacoba. Biasanya merek-merek ini adalah merek yang sering dibeli dan digunakan (convenience goods), dimana merek ini tidak mahal dan digunakan dengan segera dan membutuhkan pertimbangan atau informasi yang detail dalam melakukan keputusan membeli.

Selain itu untuk menumbuhkan perubahan prilaku tergantung pada atribut supermarket yang terdiri Fasilitas yang diberikan, pelayanan yang diberikan, after sales service, penataan barang (merchandise). Atribut supermarket dapat mengakibatkan perubahan perilaku seseorang untuk melakukan pembelian tidak terencana. Hal 
ini didasarkan pada asumsi yang mengatakan bahwa jasa layanan fisik menyediakan lingkungan yang mempengaruhi perilaku konsumen, dihubungkan dengan karakteristik lingkungan konsumsi fisik (Bitner, Booms dan Tetreault, 1990; Cole dan Gaeth, 1990; Eroglu dan Machleit, 1990; Iyer, 1989). Selanjutnya dikatakan bahwa suasana lingkungan belanja dapat mengubah emosi konsumen dan pengalaman berbelanja (Donovan dan Rossiter, 1982; Donovan, Rossiter, Marcoolyn, dan Nesdale, 1994). Toko dapat menawarkan suasana atau lingkungan yang dapat mempengaruhi pola perilaku keputusan konsumen (Baker, Grewal, dan Parasuraman, 1994 : 201-202. Hatane, $2005:$ : 41-42).

Atribut supermarket ditata sedemikian rupa untuk dapat menarik konsumen seperti adanya kenyamanan berbelanja, kebersihan toko dan penataan barang yang menarik, juga karyawan yang berpakaian menarik. Tetapi dalam pelaksanaan atribut supermarket menghadapi berbagai keluhan konsumen seperti

1. Penataan barang yang ada di supermarket kadang membingungkan

2. Karyawan yang melayani kadangkala tidak bersemangat memberikan pelayanan atau dengan muka masam

Pengusaha supermarket telah berusaha mengembangkan strategi pemasarannya. Namun demikian banyaknya perubahan yang terjadi karena adanya pertama persaingan dan tuntutan pelanggan itu sendiri. Kedua belum dikembangkannya pelaksanaan atribut supermarket. Oleh karena itu perlu dilakukan suatu penelitian mengenai unsur-unsur atribut supermarket yang harus dikembangkan atau dikelola oleh pengusaha supermarket dalam mempengaruhi Impulse Buying pada Supermaket Kota Bandung.

Berdasarkan latar belakang penelitian, maka identifikasi masalahnya adalah menurunnya supermarket membuat perusahaan melakukan berbagai strategi untuk meraih konsumennya. Salah satunya adalah melakukan penataan atribut supermarket yang menarik.

Suasana supermarket yang menyenangkan diharapkan dapat membuat orang berbelanja tanpa memperdulikan produk tersebut. Tetapi keadaan supermarket yang menyenangkan membuat konsumen berbelanja untuk memenuhi kebutuhan hidup dan pembelanjaan sesuai dengan rencana. Dengan kata lain tidak melakukan kegiatan impulse buying.

Permasalahan dalam penelitian ini dapat dirumuskan adalah Sejauhmana pengaruh atribut supermarket terhadap impulse buying

\section{TINJAUAN PUSTAKA}

\section{Konsep Atribut Supermarket}

Atribut produk adalah suatu komponen yang merupakan sifat-sifat produk yang menjamin agar produk tersebut dapat memenuhi kebutuhan dan keinginan yang diharapkan oleh pembeli. Adanya atribut yang melekat pada suatu produk dapat digunakan konsumen untuk menilai dan mengukur kesesuaian atribut produk dengan kebutuhan dan keinginan. Bagi perusahaan dengan mengetahui atribut-atribut apa saja yang bisa mempengaruhi keputusan pembelian maka dapat ditentukan setrategi untuk mengembangkan dan menyempurnakan produk agar lebih memuaskan konsumen. Atribut produk meliputi mutu produk, sifat produk dan rancangan. (Kotler, $2006: 72$ )

Selain itu dikenal adanya atribut toko. Atribut toko dipandang sebagai suatu bagian keseluruhan dari image suatu toko (Bloemer dan deRuyter, 1998 dalam Trang, Tho dan Barret, 2006 : 230). Atribut toko merupakan keseluruhan atribut yang dirasakan oleh pembeli melalui pengalamannya berbelanja dalam toko (Omar, 1999 dalam Trang, Tho dan Barret, $200: 230)$. Atribut toko dapat diaplikasikan sesuai dengan bentuk dari toko tersebut, apakah itu supermarket atau hypermarket atau bentuk ritel lainnya (Trang, Tho dan Barret, 2006 : 230). Istilah lain dari atribut toko adalah atribut pengecer atau atribut ritel (Moore, 2006)

Penelitian pertama mengenai atribut toko dilakukan oleh Berry (1969, dalam Yilmax, Aktas, Celix, 2007 : 171) menerangkan tentang image toko yang mengacu pada 12 komponen yaitu harga, kualitas, kelengkapan, fashion merchandise, penjualan personal, lokasi, pelayanan, keragaman produk, promosi penjualan, periklanan, suasana toko, dan reputasi. Lindquist pada tahun 1974-1975 (dalam Trang, Tho, dan Barret, 2006 : 231) mengemukakan unsur dari atribut toko identik dengan barang dagangan, pelayanan, para langganan, fasilitas fisik, waktu yang fleksibel, promosi, store ambience, faktorfaktor institusi, kepuasan setelah transaksi 
Penelitian selanjutnya mengatakan bahwa atribut toko berkaitan dengan format ritel dan diaplikasikan dalam grosir Amerika. Studi penelitian mengatakan bahwa adanya efek lingkungan toko dalam toko grosir dan membuktikan adanya keterkaitan kedua variabel tersebut. (Hansen and Deutscher, 1977, dalam Yilmax, Aktas, Celix, 2007 : 171)

Williams (1978 dalam Yilmax, Aktas, Celix, 2007 : 171) menemukan bukti bahwa adanya hubungan antara harga, kebijakan tentang konsumen dan pilihan format. Seiders and Tigert (2000, dalam Yilmax, Aktas, Celix, 2007 : 171) membandingkan supercenter shoppers dengan traditional supermarket shoppers. Supercenter shoppers identik dengan harga rendah dan adanya keseragaman produk. Sedangkan traditional supermarket shoppers menekankan pada lokasi dan produk yang berkualitas. Keragaman produk biasanya diaplikasikan dalam bentuk ritel seperti discount store, hypermarket dan supermarket.

Penelitian yang dilakukan oleh Arnold, Reynolds (2003) tentang atribut toko memperlihatkan bahwa harga, bermacam-macam produk dan pelayanan konsumen merupakan faktor yang penting dalam menentukan format pilihan dalam kontek departemen store. Penelitian lain yang dilakukan Chain Store Age (2004, dalam Yilmax, Aktas, Celix, 2007 : 171) dalam menemukan bahwa dalam literatur yang digunakan sama, yaitu mengidentifikasi keragaman produk, ketersediaan produk, produk yang sesuai dan harga merupakan motor penggerak pilihan format.

Fox (2004 dalam Yilmax, Aktas, Celix, 2007 : 171) mengidentifikasi bahwa promosi toko dan keragaman produk merupakan faktor yang sangat berkaitan dengan pilihan format pada toko grosir. Yang menarik harga tidak begitu kentara. Penelitian inipun menyarankan bahwa frekuensi pembelian berasal dari mass merchandisers yang dapat memacu frekuensi pembelian untuk traditional supermarkets.

Koo (2003, dalam Trang, Tho dan Barret, 2006 : 230) mengemukakan 7 (tujuh) komponen yaitu suasana toko, lokasi, fasilitas, nilai pelanggan, pelayanan konsumen, , pelayanan setelah pembelian, dan barang dagangan.

Trang, Tho dan Barret (2006 : 231) menekankan atribut toko pada suasana, lokasi dan fasilitas. Selanjutnya dikembangkan konsep dari atribut toko menjadi atribut supermarket disesuaikan dengan keadaan sebenarnya. Atribut ini berkaitan dengan Fasilities, Employee services, After sales services, Merchandise.

\section{Konsep Impulse Buying}

Impulse buying merupakan bagian dari teori prilaku yang berkembang sekitar tahun 1970an. Menurut Sherhorn, Reisch dan Rabb (1990, dalam Tremblay, 2005 : 4) Penelitian pertama tentang impulse buying berkaitan dengan konsumsi, dan dilakukan oleh dua tim yang berasal dari Amerika dan Canada. Kedua tim ini adalah tim American Faber dan O'Guinn dari Amerika dan Canadian Valence dan D'Astous dari Canada. Penelitian yang dilakukan oleh dua grup tersebut menyediakan informasi tentang kebiasaan mengkonsumsi yang dilakukan konsumen. Berdasarkan penelitian tersebut diketahui bahwa impulse buying dipengaruhi oleh faktor individu dan lingkungan.

Penelitian selanjutnya yang dilakukan Dittmar and Drury (1999, dalam Tremblay, $2005: 4)$ mengatakan bahwa Impulse buying pun dapat mempengaruhi aspek sosial dan aspek ekonomi. Menurut Dittmar, Beattie and Friese (1995, dalam Tremblay, $2005: 4$ ) Impulse buyingpun dapat dijabarkan dari teori yang spesifik. Teori Self Completion dapat membantu menjelaskan dari segi psikologi sosial yang merupakan aspek prilaku impulsif Teori SelfCompletion menjelaskan bahwa ketika pengalaman individual dapat dikendalikan, maka kegiatan pembelian impulsive rendah, tetapi sebaliknya bila kegiatan pengalaman berbelanja tidak dapat dikendalikan, maka kegiatan impulse buying terjadi. Dittmar, Beattie dan Friese (1995, dalam Tremblay, 2005 : 4) mengembangkan teori yang ada dengan menambahkan faktor emosi berdasarkan perasaan yang merupakan nilai dalam pembelian. Artinya objek material dari adalah menciptakan perasaan yang penuh kegembiraan untuk bersenang-senang dan pemenuhan kebutuhan dalam jangka pendek.

Impulse buying dapat menggambarkan sesuatu prilaku yang tidak terencana, tidak beraturan, dan spontanitas. Sebagai contoh pembelian impulsif terjadi ketika adanya dorongan untuk membeli sesuatu selain menghabiskan waktu dan perhatian untuk membeli barang ketika masuk ke dalam (Baumeister, 2002 : 10). Pembelian yang tidak terencana terjadi ketika konsumen tidak biasa atau tidak familiar dengan layout toko atau kendala waktu yang sedikit (Shoham, Brencic, $2003:$ 45). 
Dorongan dalam impulse merupakan hal penting dan mempunyai nilai tersendiri untuk individu dan industri pemasaran. Berdasarkan studi penelitian yang dilakukan Dittmar, Beattie dan Friese (1995, dalam Tremblay, 2005 : 4) dikatakan bahwa pembelian impulse sekitar $50 \%$ yang dihabiskan konsumen di dalam toko. Dittmar, Beattie and Friese (1995, dalam Tremblay, 2005 : 4) mengusulkan bahwa prilaku impulse merupakan pertumbuhan yang significant. Dengan kata lain tergantung dari kondisi yang ada.

Bellenger, Robertson and Hirschman (1978) Stern (1962, dalam Evans, Jamal, Foxall, 2007: 88) mengatakan kegiatan impulse buying terbagi beberapa bentuk yaitu :

Pertama, reminder impulse buying yakni terjadi pada saat konsumen di toko, melihat produk dan kemudian membuatnya mengingat sesuatu akan produk tersebut. Bisa jadi dia ingat iklannya atau rekomendasi orang.

Kedua, pure impulse buying terjadi ketika si konsumen benar-benar tidak merencanakan apapun untuk membeli.

Ketiga, suggested impulse buying dimana si pembelanja diperkenalkan produk tersebut melalui in store promotion.

Keempat, planned impulse buying, di mana si konsumen sebenarnya mempunyai rencana namun keputusan membelinya tergantung pada harga dan merek di toko tersebut.

Impulse purchase dapat dijelaskan sebagai dorongan untuk membeli sesuatu tanpa adanya perhatian atau rencana, kemudian kegiatan impulse terjadi tanpa berkaitan dengan tujuan jangka panjang atau rencana-rencana. (Baumeister, 2002 : 10). Prilaku impulse buying terjadi apabila sesorang yang melakukan pembelian impulsif mempunyai pengendalian diri yang minim (Faber, O'Guinn, 1989 : 8).

Penelitian yang dilakukan oleh Jones, Reynolds, Weun and Beatty (2003) argues that an impulse shopper experiences an immediate gratification upon purchasing. Consumers utilizing cognition will be more likely to make rational purchases, decisions, and make fewer impulse purchases; consumers who are more emotional will be more likely to make impulsive purchases (Coley and Burgess, 2003).

Tekanan waktu merupakan faktor penting yang berhubungan dengan pembelian atau motif impulse. lyer (1989) dalam penelitiannya menemukan bahwa adanya ketidakleluasaan waktu, ketika seseorang menghabiskan waktunya dan berbelanja di toko. Konsumen dalam melakukan pembelian impulsive dibatasi limit waktu dibandingkan waktu yang tidak dibatasi.

Stern (1962, dalam Evans, Jamal, Foxall, 2007: 88) mengidentifikasi hubungan sembilan karakteristik produk yang mungkin dapat mempengaruhi pembelian impulsif yaitu harga rendah, kebutuhan tambahan produk atau merek, distribusi massa, self service, iklan massa, display produk yang menonjol, umur produk yang pendek, ukuran kecil dan mudah disimpan. Kollat dan Willet (1967, dalam Bayley, Nancarrow, 1998 : 100) memperkenalkan tipologi perencanaan sebelum didasarkan pada tingkat perencanaan sebelum masuk toko, meliputi perencanaan terhadap produk dan merek produk, kategori produk, kelas produk, kebutuhan umum yang ditetapkan, dan kebutuhan umum yang belum ditetapkan. Beberapa peneliti beranggapan bahwa impulse buying sinonim dengan unplanned buying ketika para psikolog dan ekonom memfokuskan pada aspek irrasional atau pembelian impulsive murni (Bayley dan Nancarrow, 1998).

Engel dan Blacwell (1982, dalam Bayley, Nancarrow, 1998 : 100) mendefinisikan unplanned buying adalah suatu tindakan pembelian yang dibuat tanpa direncanakan sebelumnya atau keputusan pembelian dilakukan pada saat berada di dalam toko. Cobb dan Hayer (1986, dalam Bayley, Nancarrow, 1998 : 100) mengklasifikan suatu pembelian impulsive terjadi apabila tidak terdapat tujuan pembelian merek tertentu atau kategori produk tertentu pada saat masuk ke dalam toko.

Thomson (1990, dalam Bayley, Nancarrow, 1998 : 101) mengemukakan bahwa ketika terjadi pembelian impulsive akan memberikan pengalaman emosional lebih dari pada rasional, sehingga tidak dilihat sebagai sugesti, dengan dasar ini maka pembelian impulsive lebih dipandang sebagai keputusan rasional dibandingkan irrasional. Bayley dan Nancarrow (1998: 101) tidak membedakan antara unplanned buying dengan impulse buying, tetapi memberikan perhatian penting kepada periset pelanggan harus menfokuskan pada interaksi antara point-of sale dengan pembeli yang sering diabaikan.

Penelitian yang dilakukan Hausman $(2000: 404)$ menjelaskan bahwa impulse buying merupakan bagian dari pembelian yang tidak terencana. Dalam melakukan kegiatan impulse buying adalah melakukan pembelian tanpa melihat manfaat dari 
pembelian tersebut. Intinya impulse buying berkaitan dengan keputusan.

Selanjutnya definisi dari impulse buying sebagai berikut :

\begin{tabular}{|l|l|l|}
\hline No. & Pendapat & Definisi Impulse Buying \\
\hline 1. & $\begin{array}{l}\text { Rook dan Fisher } \\
(2007)\end{array}$ & $\begin{array}{l}\text { impulse buying sebagai } \\
\text { kecenderungan konsumen } \\
\text { untuk membeli secara spontan, } \\
\text { reflek, tiba-tiba dan otomatis }\end{array}$ \\
\hline 2. & $\begin{array}{l}\text { Mowen dan } \\
\text { Minor (2001 : } \\
65)\end{array}$ & $\begin{array}{l}\text { Pembelian impulsif (Impulse } \\
\text { Buying) adalah tindakan } \\
\text { membeli yang dilakukan tanpa } \\
\text { memiliki masalah sebelumnya } \\
\text { atau maksud/niat membeli } \\
\text { yang terbentuk sebelum } \\
\text { memasuki toko }\end{array}$ \\
\hline 3. & $\begin{array}{l}\text { Schiffman dan } \\
\text { Kanuk (2007 : } \\
511)\end{array}$ & $\begin{array}{l}\text { impulse buying merupakan } \\
\text { keputusan yang emosional } \\
\text { atau menurut desakan hati }\end{array}$ \\
\hline 4. & $\begin{array}{l}\text { Shoham dan } \\
\text { Brencic (2003) }\end{array}$ & $\begin{array}{l}\text { impulse buying berkaitan } \\
\text { dengan prilaku untuk membeli } \\
\text { berdasarkan emosi. }\end{array}$ \\
\hline 5. & $\begin{array}{l}\text { Martin Evans, } \\
\text { Ahmad Jamal } \\
\text { and Gordon } \\
\text { Foxall } \\
\text { (2006:87) }\end{array}$ & $\begin{array}{l}\text { Impulse buying are to some } \\
\text { extent dependent upon some } \\
\text { level of prior understanding and } \\
\text { interest in the product or } \\
\text { service }\end{array}$ \\
\hline
\end{tabular}

Sumber : diolah dari berbagai literatur

\section{Keterkaitan Attribut Supermarket dengan Impulse Buying}

Perilaku berbelanja adalah perilaku yang membutuhkan suasana hati yang menyenangkan. Semakin para peritel/perusahaan membuat atribut supermarket/hypermarket menarik semakin dapat menggaet pengunjung untuk bertransaksi. Dengan kata lain terjadinya suatu proses pengambilan keputusan konsumen yang didasarkan pada hati/faktor emosi. Ini menandakan terjadinya suatu kegiatan impulse buying. (M. Taufiq Amir, 2004 ; 26-27)

Hal senada diungkapkan dalam penelitian yang dilakukan Gutieerez (2004 : 1064) atribut supermarket mempengaruhi kegiatan impulse buying. Hal ini terjadi apabila adanya penataan barang dan kelengkapan barang yang disajikan. Kelengkapan ini biasanya disertai katalog yang berguna bagi konsumen yang akan membeli. Selain itu adanya kejelasan penempatan barang dalam melakukan kegiatan pembelian. Ini menandakan bahwa terjadinya impulse buying karena adanya kategori produk atau atribut produk yang ditawarkan oleh toko tersebut (Bayley, Nancarrow, 1998 : 101)

Keputusan pembelian yang dilakukan belum tentu direncanakan, terdapat pembelian yang tidak direncanakan (impulsive buying) akibat adanya rangsangan lingkungan belanja. Implikasi dari lingkungan belanja terhadap perilaku pembelian mendukung asumsi bahwa jasa layanan fisik menyediakan lingkungan yang mempengaruhi perilaku konsumen, dihubungkan dengan karakteristik lingkungan konsumsi fisik (Bitner, Booms dan Tetreault, 1990; Cole dan Gaeth, 1990; Eroglu dan Machleit, 1990; lyer, 1989). Secara spesifik, dokumentasi mengenai suasana sebuah lingkungan belanja serta lingkungan retail dapat mengubah emosi konsumen (Donovan dan Rossiter, 1982; Donovan, 1994)

Pendapat serupa diungkapkan oleh Ndubisi (2005 : 35) dan Hatane (2006 : 157) impulse buying terjadi apabila adanya rangsangan atribut supermarket atau hypermarket /lingkungan berbelanja. Hal ini berkaitan dengan faktor fisik yang ada pada bentuk ritel tersebut.

\section{Kerangka Pemikiran}

Supermarket merupakan suatu toko modern yang melayani penjualan makanan, daging, serta produk-produk makanan lainnya, serta melakukan pembatasan penjualan terhadap produk-produk non makanan, seperti produk kesehatan, kecantikan dan produk-produk umum lainnya. Supermarket ini meruapakan cikal bakal dari pengembangan supermarket lainnya seperti warehouse, hipermarket dan sebagainya.

Dalam perkembangannya supermarket mengalami penurunan dibandingkan hipermarket atau ritel lainnya. Hal ini berdampak pada keuntungan perusahaan. Oleh karena itu supermarket menata kembali tokonya dan menawarkan atribut yang ada pada toko tersebut atau dikenal dengan atribut supermarket. Atribut supermarket berkaitan dengan fasilitas yang diberikan oleh toko tersebut, pelayanan karyawan, pelayanan setelah pembelian dan barang/produk. Respon konsumen ini sangatlah beragam. Salah satunya adalah perilaku yang berkaitan dengan emosi seseorang. Pernyataan di atas didukung oleh penelitian yang dilakukan oleh Ndubisi (2005: 34-35) dan Hatane (200 : 157) impulse buying terjadi apabila adanya rangsangan atribut supermarket/lingkungan berbelanja. Selain itu pula 
atribut supermarket mengacu pada semua karakteristik fisik dan sosial konsumen, termasuk objek fisik (produk dan toko), hubungan ruang (lokasi toko dan produk dalam toko), dan perilaku sosial dari orang lain (siapa saja yang di sekitar dan apa saja yang mereka lakukan). Implikasi dari atribut supermarket terhadap perilaku pembelian mendukung asumsi bahwa jasa layanan fisik menyediakan lingkungan yang mempengaruhi perilaku konsumen, dihubungkan dengan karakteristik lingkungan konsumsi fisik (Bitner, Booms dan Tetreault, 1990; Cole dan Gaeth, 1990; Eroglu dan Machleit, 1990; lyer, 1989). Secara spesifik, suasana sebuah lingkungan belanja serta lingkungan ritel khususnya supermarket dapat mengubah emosi konsumen (Donovan dan Rossiter, 1982; Donovan, 1994). Perubahan emosi mengubah suasana hati konsumen yang mempengaruhi keduanya yaitu perilaku pembelian dan evaluasi tempat belanja konsumen semula (Babin, Darden dan Griffin, 1994; Dawson, Bloch dan Ridgway, 1990; Gardner, 1985). Supermarket dapat menawarkan suasana atau lingkungan yang dapat mempengaruhi pola perilaku keputusan. konsumen (Baker, Grewal, dan Parasuraman, 1994). Lingkungan belanja dapat mempengaruhi seseorang untuk melakukan pembelian tidak terencana. Artinya atribut hypermarket mempunyai dampak terhadap impulse buying Gutieerez (2004 : 1063-1064). Hal ini dapat digambarkan dalam kerangka pemikiran berikut ini :

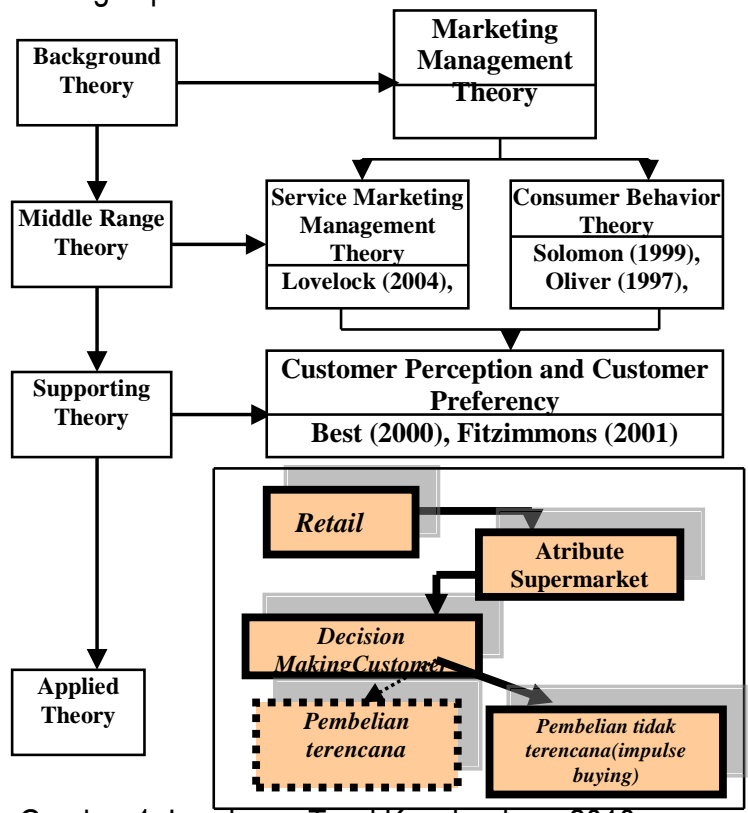

Gambar 1. Landasan Teori Keseluruhan, 2010

\section{HASIL PENELITIAN DAN PEMBAHASAN}

1. Analisis Regresi Linear Berganda Perhitungan Koefisien regresi

$Y=\hat{a}+b_{1} X_{1}+b_{2} X_{2}+b_{3} X_{3}+b_{4} X_{4}+b_{5} X_{5}$

Berdasarkan persamaan regresi linear berganda di atas, maka nilai koefisien regresinya diperoleh dari matrik berikut ini :

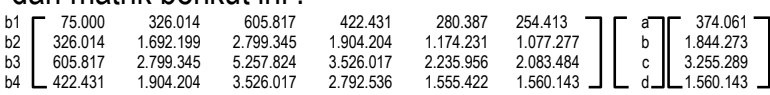

a. Operasi b1:

$\left[\begin{array}{rrrrrr}75.000 & 326.014 & 605.817 & 422.431 & 280.387 & 254.413 \\ 0.000 & 1.366 .184 & 2.473 .330 & 1.578 .189 & 848.217 & 751.262 \\ 0.000 & 2.192 .527 & 4.651 .006 & 2.919 .199 & 1.629 .138 & 1.476 .667 \\ 0.000 & 1.481 .773 & 3.103 .586 & 2.370 .105 & 1.132 .992 & 1.137 .713\end{array}\right]$

b. Operasi b2:

$\left[\begin{array}{rrrrrr}75.000 & 326.014 & 605.817 & 422.431 & 280.387 & 254.413 \\ 0.000 & 1.366 .184 & 2.473 .330 & 1.578 .189 & 848.217 & 751.262 \\ 0.000 & 0.000 & 2.458 .479 & 726.672 & -563.389 & -715.861 \\ 0.000 & 0.000 & 1.621 .813 & 888.332 & -348.781 & -344.060\end{array}\right]$

c. Operasi b3:

$\left[\begin{array}{rrrrrr}75.000 & 326.014 & 605.817 & 422.431 & 280.387 & 254.413 \\ 0.000 & 1.366 .184 & 2.473 .330 & 1.578 .189 & 848.217 & 751.262 \\ 0.000 & 0.000 & 2.458 .479 & 726.672 & -563.389 & -715.861 \\ 0.000 & 0.000 & 0.000 & -733.481 & -1.970 .594 & -1.965 .873\end{array}\right]$

d. Operasi b4:

$\left[\begin{array}{rrrrrr}75.000 & 326.014 & 605.817 & 422.431 & 280.387 & 254.413 \\ 0.000 & 1.366 .184 & 2.473 .330 & 1.578 .189 & 848.217 & 751.262 \\ 0.000 & 0.000 & 2.458 .479 & 726.672 & -563.389 & -715.861 \\ 0.000 & 0.000 & 0.000 & -733.481 & -1.970 .594 & -1.965 .873\end{array}\right]$

e. Operasi b4:

$\left[\begin{array}{rrrrrr}75.000 & 326.014 & 605.817 & 422.431 & 280.387 & 254.413 \\ 0.000 & 1.366 .184 & 2.473 .330 & 1.578 .189 & 848.217 & 751.262 \\ 0.000 & 0.000 & 2.458 .479 & 726.672 & -563.389 & -715.861 \\ 0.000 & 0.000 & 0.000 & -733.481 & -1.970 .594 & -1.965 .873\end{array}\right]\left[\begin{array}{l}\mathrm{a} \\ \mathrm{b} \\ \mathrm{c} \\ \mathrm{d}\end{array}\right]\left[\begin{array}{l}374.061 \\ 1.844 .273 \\ 3.255 .289 \\ 2.184 .778\end{array}\right]$

Matrik perhitungan koefisien regresi tersebut akan digunakan untuk mendapatkan nilai koefisien regresi sehingga terbentuk sebuah persamaan regresi, maka perhitungan koefisien regresi sebagai berikut :

$\hat{Y}=0,190+3,805 X_{1}+1,708 X_{2}+-2,137 X_{3}+-$ $0,278 \mathrm{X}_{4}$

\section{Perhitungan Korelasi}

Dalam perhitungan korelasi diperlukan langkahlangkah :

A. Perhitungan Jumlah Kuadran Untuk Setiap Variabel Penelitian

(1) Jumlah kuadrat setiap variabel atribut supermarket $(\mathrm{X})$ dan impulse buying $(\mathrm{Y})$

$$
J K X_{k}=\Sigma X_{k}^{2}-\frac{\left(X_{k}\right)^{2}}{n}
$$


- $\quad$ Nilai jumlah kuadrat X1 (fasilitas)

$J K X_{1}=1692.199-\frac{(326.014)^{2}}{75}=275.060$

- Nilai jumlah kuadrat X2 (Employee service)

$J K X_{2}=5257.824-\frac{(606.817)^{2}}{75}=348.125$

- Nilai jumlah kuadrat X3 (Aftersales service)

$J K X_{3}=2792.536-\frac{(422.431)^{2}}{75}=413.235$

- $\quad$ Nilai jumlah kuadrat X4 (Merchandise)

$$
\begin{aligned}
& J K X_{4}=\Sigma X_{4}^{2}-\frac{\left(X_{4}\right)^{2}}{n} \\
& J K X_{4}=621.208-\frac{(204.317)^{2}}{75}=129.606
\end{aligned}
$$

- $\quad$ Nilai jumlah kuadrat $Y$ (Impulse Buying)

$$
\begin{aligned}
& J K Y=\Sigma Y^{2}-\frac{(Y)^{2}}{n} \\
& J K Y=2244.140-\frac{(374.061)^{2}}{75}=378.518
\end{aligned}
$$

(2) Jumlah Kuadrat setiap variabel atribut supermarket $(X)$ terhadap impulse buying $(Y)$

$$
K X_{k} Y=\Sigma X_{k} Y-\frac{\left[\Sigma X_{k} \Sigma Y\right]}{n}
$$

- Nilai jumlah kuadrat variabel X1 (fasilitas) terhadap variabel $Y$ (Impulse Buying)

$J K X_{1} Y=1844.273-\frac{(326.041)(374.061)}{75}=218.282$

- Nilai jumlah kuadrat variabel $\mathrm{X} 2$ (Employee service) terhadap variabel $Y$ (Impulse Buying)

$J K X_{2} Y=3255.289-\frac{(606817)(374.061)}{75}=228.799$

- Nilai jumlah kuadrat variabel $X 3$ (Aftersales service) terhadap variabel $Y$ (Impulse Buying)

$$
J K X_{3} Y=2184.778-\frac{(422.431)(374.061)}{75}=77.914
$$

- Nilai jumlah kuadrat variabel $\mathrm{X} 4$ (merchandise) terhadap variabel $Y$ (Impulse Buying)

$$
J K X_{4} Y=1361.997-\frac{(204.317)(374.061)}{75}=-36.428
$$

(3) Jumlah kuadrat antar variabel atribut spermarket $(X)$

$$
J K X_{k} X_{k}=\Sigma X_{k} X_{k}-\left[\frac{\Sigma X_{k} \Sigma X_{k}}{n}\right]
$$

- Nilai jumlah kuadrat variabel X1 (fasilitas) terhadap X2 (Employee service)

$$
J K X_{1} X_{2}=2799.345-\frac{(326.041)(606.817)}{75}=161.595
$$

- Nilai jumlah kuadrat variabel X1 (fasilitas) terhadap X3 (Aftersales service)

$$
J K X_{1} X_{3}=1904.204-\frac{(326.041)(422.431)}{75}=67.958
$$

- Nilai jumlah kuadrat variabel X1 (fasilitas) terhadap X4 (Merchandise)

$$
J K X_{1} X_{4}=1174.231-\frac{(326.041)(204.317)}{75}=-44.572
$$

- Nilai jumlah kuadrat variabel $\mathrm{X} 2$ (Employee service) terhadap X3 (Aftersales service)

$$
J K X_{2} X_{3}=3526.017-\frac{(606.817)(422.431)}{75}=108.174
$$

- Nilai jumlah kuadrat variabel $\mathrm{X} 2$ (Employee service) terhadap X4 (merchandise)

$J K X_{2} X_{4}=2235.956-\frac{(606.817)(204.317)}{75}=-32.628$

- Nilai jumlah kuadrat variabel X3 (Aftersales service) terhadap $\mathrm{X} 4$ (merchandise)

$$
J K X_{3} X_{4}=1555.422-\frac{(422.431)(204.317)}{75}=-23.8321
$$

Hasil perhitungan di atas dapat dilihat pada tabel di bawah ini :

\begin{tabular}{|l|c|c|c|c|c|}
\hline $\mathrm{JK}$ & $\mathrm{X}_{1}$ & $\mathrm{X}_{2}$ & $\mathrm{X}_{3}$ & $\mathrm{X}_{4}$ & $\mathrm{Y}$ \\
\hline $\mathrm{X}_{1}$ & 275.060 & 161.595 & 67.958 & -44.572 & 218.282 \\
\hline $\mathrm{X}_{2}$ & & 348.125 & 108.174 & -32.628 & 228.799 \\
\hline $\mathrm{X}_{3}$ & & & 413.235 & -23.832 & 77.914 \\
\hline $\mathrm{X}_{4}$ & & & & & -36.428 \\
\hline $\mathrm{Y}$ & & & & & 378.518 \\
\hline
\end{tabular}

Sumber : Data primer yang telah diolah tahun 2010 
B. Nilai jumlah kuadrat Regresi

$$
\begin{aligned}
\text { Jkreg }= & b \Sigma X 1 Y+c \Sigma X 2 Y+d \Sigma X 3 Y+e \Sigma X 4 Y+f \Sigma X 5 Y \\
= & 0.214(218,282)+1.156(228.799)+(- \\
& 0.404)(77.914)+(-0.205)(-36.428) \\
= & 287.194
\end{aligned}
$$

\section{Nilai Jumlah Kuadrat Residu}

$$
\begin{aligned}
\mathrm{JK}_{\text {res }} & =\mathrm{JK}_{\text {tot }}-\mathrm{JK}_{\text {reg }} \\
& =378.518-287.194 \\
& =91.324
\end{aligned}
$$

D. Perhitungan Korelasi Parsial Variabel Atribut Supermarket $(\mathrm{X})$ dan Variabel Impulse Buying

(1) Nilai korelasi parsial setiap variabel atribut supermarket $(X)$ terhadap variabel impulse buying $(\mathrm{Y})$.

$$
r_{b}=\frac{\sum X_{k} Y}{\sqrt{\sum X_{k}^{2} \sum Y^{2}}}
$$

- Nilai korelasi parsial variabel X1 (fasilitas) terhadap variabel $Y$ (Impulse Buying)

$$
r_{x_{1} y}=\frac{218.282}{\sqrt{(275.060)(378.518)}}=0.676
$$

- Nilai korelasi parsial variabel X2 (employee service) terhadap variabel $Y$ (Impulse Buying)

$$
r_{x_{2} y}=\frac{228.799}{\sqrt{(348.125)(378.518)}}=0.630
$$

- Nilai korelasi parsial variabel X3 (aftersales service) terhadap variabel $Y$ (Impulse Buying)

$$
r_{x_{3} y}=\frac{77.914}{\sqrt{(413.235)(378.518)}}=0.197
$$

- Nilai korelasi parsial variabel $\mathrm{X} 4$ (merchandise) terhadap variabel $Y$ (Impulse Buying)

$$
r_{x_{4} y}=\frac{-36.428}{\sqrt{(129.606)(378.518)}}=-0.164
$$

(2) Nilai korelasi parsial (individu) antar variabel promosi penjualan $(X)$

$$
r_{k}=\frac{\Sigma X_{k} X_{k}}{\sqrt{\Sigma X_{k}^{2} \Sigma Y^{2}}}
$$

- Nilai korelasi parsial variabel X1 (fasilitas) terhadap variabel X2 (Employee Service)

$$
r_{x_{1} x_{2}}=\frac{161.595}{\sqrt{(275.060)(378.518)}}=0.522
$$

- Nilai korelasi parsial variabel X1 (fasilitas) terhadap variabel X3 (Aftersales Service)

$$
r_{x_{1} x_{3}}=\frac{67.958}{\sqrt{(275.060)(378.518)}}=0.202
$$

- Nilai korelasi parsial variabel X1 (fasilitas) terhadap variabel $\mathrm{X} 4$ (merchandise)

$$
r_{x_{1} x_{4}}=\frac{-44.572}{\sqrt{(275.060)(378.518)}}=-0.236
$$

- Nilai korelasi parsial variabel X2 (Employee Service) terhadap variabel X3 (Aftersales Service)

$$
r_{x_{2} x_{3}}=\frac{108.174}{\sqrt{(348.125)(378.518)}}=0.285
$$

- Nilai korelasi parsial variabel X2 (Employee Service) terhadap variabel X4 (merchandise)

$$
r_{x_{2} x_{4}}=\frac{-32.628}{\sqrt{(348.125)(378.518)}}=-0.154
$$

- Nilai korelasi parsial variabel X3 (Aftersales Service) terhadap variabel X4 (merchandise)

$$
r_{x_{3} x_{4}}=\frac{-23.8321}{\sqrt{(413.235)(378.518)}}=-0.103
$$

\begin{tabular}{|c|c|c|c|c|}
\hline$r$ & $X_{2}$ & $X_{3}$ & $X_{4}$ & $Y$ \\
\hline$X_{1}$ & 0.522 & 0.202 & -0.236 & 0.676 \\
\hline$X_{2}$ & & 0.285 & -0.154 & 0.630 \\
\hline$X_{3}$ & & & -0.103 & 0.197 \\
\hline$X_{4}$ & & & & -0.164 \\
\hline
\end{tabular}

Sumber : Data primer yang telah diolah 2009

\section{E. Koefisien Determinasi}

$$
R^{2}=\frac{J K_{\text {res }}}{J K_{\text {total }}}=\frac{91.324}{378.518}=0,25
$$

\section{F. Koefisien Korelasi Total}

$$
r_{x y}=\sqrt{R^{2}}=\sqrt{0,25}=0.5
$$


G. Koefisien Error

$R_{2 \varepsilon}^{2}=1-R^{2}$

$=1-0.5$

$=0.5$

$r_{\varepsilon}=\sqrt{0,5}=0.71$

\section{Pengujian Hipotesis}

Menurut Syafaruddin Siregar (2004:234) untuk menentukan penerimaan atau penolakan hipotesis, maka dilakukan pengujian signifikansi regresi linier berganda menggunakan :

1. Uji hubungan regresi dengan uji $F$

$$
F_{h}=\frac{\frac{R^{2}}{k}}{\frac{\left(1-R^{2}\right)}{(n-k-1)}}=\frac{\frac{0.25}{24}}{\frac{(1-25)}{(75-24-1)}}=0,007
$$

a. Uji Hipotesis

Ho : persamaan regresi ditolak

$\mathrm{Ha}$ : persamaan regresi diterima

b. Kaidah pengujian

Jika $F_{\text {hitung }} \geq F_{\text {tabel, }}$ maka Ho ditolak (persamaan regresi diterima)

Jika $F_{\text {hitung }} \leq \mathrm{F}_{\text {tabel, }}$ maka Ho diterima (persamaan regresi ditolak)

c. Perhitungan uji $F$ yaitu sebagai berikut :

Berdasarkan nilai pada tabel $F$ untuk jumlah sampel sebanyak 75 responden maka persamaan regresi diterima atau secara keseluruhan variabel atribut supermarket memberikan pengaruh terhadap impulse buying.

2. Uji Koefisien Korelasi Keseluruhan dengan uji t

$$
t=r \sqrt{\frac{n-2}{1-r^{2}}}=0.71 \sqrt{\frac{75-2}{1-0.71^{2}}}=8,62
$$

a. Uji Hipotesis

Ho : Tidak ada pengaruh yang signifikan dari atribut supermarket secara bersamasama terhadap impulse buying

$\mathrm{Ha}$ : Ada pengaruh yang signifikan dari atribut supermarket secara bersama-sama terhadap impulse buying

b. Kaidah pengujian Jika $t_{\text {hitung }} \geq \mathrm{t}_{\text {tabel, }}$ maka Ho ditolak (signifikan) Jika thitung $\leq t_{\text {tabel, }}$ maka Ho diterima (tidak signifikan)

c. Perhitungan uji t yaitu sebagai berikut :

Berdasarkan nilai pada tabel $t$ untuk jumlah sampel sebanyak 75 responden diperoleh nilai $t$ tabel sebesar 1.32 , sehingga diketahui thitung $\geq$ tabel yaitu $8.62 \geq 1.32$, maka keseluruhan variabel atribut supermarket memberikan pengaruh yang signifikan terhadap impulse buying.

3. Pengujian koefisien korelasi secara parsial dihitung dengan uji t sebagai berikut:

$$
t_{a i}=\frac{a i}{S_{a i}}
$$

Koefisienb $=0.214$

$S_{b}^{2}=\frac{J K_{\text {res }} /(n-k-1)}{J K x 1\left(1-R^{2}\right)}=\frac{91324 /(75-24-1)}{275.060(1-0.951)}=0,136$

$t_{b}=\frac{b}{S_{b}}=\frac{0.214}{0,136}=1,574$

a. Uji Hipotesis

Ho : Tidak ada pengaruh yang signifikan dari fasilitas terhadap impulse buying

$\mathrm{Ha}$ : Ada pengaruh yang signifikan dari fasilitas terhadap impulse buying

b. Kaidah pengujian

Jika thitung $\geq t_{\text {tabel, }}$ maka Ho ditolak (signifikan)

Jika thitung $\leq t_{\text {tabel, }}$ maka Ho diterima (tidak signifikan)

c. Perhitungan uji t yaitu sebagai berikut :

Berdasarkan nilai pada tabel $t$ untuk jumlah sampel sebanyak 75 responden diperoleh nilai $t$ tabel sebesar 1.32 , sehingga diketahui thitung $\leq$ tabel yaitu $1,574 \geq 1.32$, maka fasilitas mempunyai pengaruh yang tidak signifikan terhadap impulse buying.

Koefisien $\mathrm{c}=1.156$

$$
\begin{aligned}
& S_{b}^{2}=\frac{J K_{r e s} /(n-k-1)}{J K x 2\left(1-R^{2}\right)}=\frac{91.324 /(75-24-1)}{348.125(1-0.951)}=0.11 \\
& t_{b}=\frac{b}{S_{c}}=\frac{1.156}{0.11}=10,5
\end{aligned}
$$

a. Uji Hipotesis

Ho : Tidak ada pengaruh yang signifikan dari employee service terhadap impulse buying

$\mathrm{Ha}$ : Ada pengaruh yang signifikan dari employee service terhadap impulse buying

b. Kaidah pengujian

Jika $t_{\text {hitung }} \geq \mathrm{t}_{\text {tabel, }}$, maka Ho ditolak (signifikan) Jika thitung $\leq t_{\text {tabel, }}$ maka Ho diterima (tidak signifikan)

c. Perhitungan uji t yaitu sebagai berikut : 
Berdasarkan nilai pada tabel $\mathrm{t}$ untuk jumlah sampel sebanyak 75 responden diketahui $t_{\text {hitung }} \leq t_{\text {tabel }}$ yaitu $10,5 \geq 1.32$, maka employee service mempunyai pengaruh yang tidak signifikan terhadap impulse buying.

Koefisien $d=-0.404$

$S_{b}^{2}=\frac{J K_{\text {res }} /(n-k-1)}{J K x 2\left(1-R^{2}\right)}=\frac{91.324 /(75-24-1)}{413.325(1-0.951)}=0.09$

$t_{b}=\frac{b}{S_{c}}=\frac{-0.404}{0.09}=-4,49$

a. Uji Hipotesis

Ho : Tidak ada pengaruh yang signifikan dari after sales service terhadap impulse buying

$\mathrm{Ha}$ : Ada pengaruh yang signifikan dari after sales service terhadap impulse buying

b. Kaidah pengujian

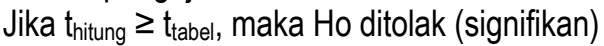

Jika thitung $\leq t_{\text {tabel, }}$, maka Ho diterima (tidak signifikan)

c. Perhitungan uji t yaitu sebagai berikut :

Berdasarkan nilai pada tabel $t$ untuk jumlah sampel sebanyak 75 responden diketahui thitung $\leq t_{\text {tabel }}$ yaitu $-4,49 \leq 1.32$, maka after sales service mempunyai pengaruh yang tidak signifikan terhadap impulse buying.

Koefisien e $=-0.205$

$S_{b}^{2}=\frac{J K_{\text {res }} /(n-k-1)}{J K x 2\left(1-R^{2}\right)}=\frac{91.324 /(75-24-1)}{129.606(1-0.951)}=0.29$

$t_{b}=\frac{b}{S_{c}}=\frac{-0.205}{0,29}=-0.71$

a. Uji Hipotesis

Ho : Tidak ada pengaruh yang signifikan dari merchandise terhadap impulse buying

$\mathrm{Ha}$ : Ada pengaruh yang signifikan dari merchandise terhadap impulse buying

b. Kaidah pengujian

Jika $t_{\text {hitung }} \geq t_{\text {tabel, }}$, maka Ho ditolak (signifikan)

Jika thitung $\leq t_{\text {tabel, }}$ maka Ho diterima (tidak signifikan)

c. Perhitungan uji t yaitu sebagai berikut :

Berdasarkan nilai pada tabel $t$ untuk jumlah sampel sebanyak 75 responden diketahui thitung $\leq t_{\text {tabel }}$ yaitu $-0.71 \leq 1.32$, maka merchandise mempunyai pengaruh yang tidak signifikan terhadap impulse buying.

\section{KESIMPULAN DAN SARAN}

1. Kesimpulan

Atribut supermarket mempunyai pengaruh secara simultan dan parsial terhadap impulse buying. Hal ini berarti jika atribut supermarket dilaksanakan dengan baik maka akan meningkatkan daya beli konsumen dalam hal ini adalah impulse buying. Tetapi dalam pelaksanaannya terdapat hambatan seperti penataan barang yang kadang membingungkan dan pelayanan karyawan yang kurang baik

2. Saran

a. Penataan supermarket harus diatur kembali

b. Adanya garansi penukaran barang sesuai perjanjian.

\section{DAFTAR PUSTAKA}

Aaker. David A., V. Kumar, George S. Day. 2004. Marketing Research Seventh Edition. John Wiley \& Sons, Inc. New York.

Abratt, Russell, and Stephen Donald Goodey, 1990, Unplanned Buying and In-Store Stimuli in Supermarkets. Managerial and Decision Economics, May, 11, 2. ABI/INFORM Global pg. 111.

Adelaar, Thomas., Susan Chang, Karen M. Lancendorfer, Byoungkwan Lee, Mariko Marimoto. 2003. Effect of Media Formats on Emotions and Impulse Buying Intent. Journal of Information Technology, 18, pp 247-266.

Babin, Barry J. and William R. Darden, 1995, Consumer Self-Regulation in a Retail Environment. Journal of Retailing, 71: 4770.

Baker, Julie., Dhruv Grewal, Parasuraman, 1994, The Influence of Store Environment on Quality Inferences and Store Image. Journal of the Academy of Marketing Science, 22 (4): 328-339.

Barker, Chris. Nabcy Pistrang. Robert Elliott. 2002. Research Methods in Clinical Psychology : An Introduction for Students and Practitioners, $2^{\text {nd }}$, John Wiley \& Sons, Ltd. England. 
Bayley, Geoff. Clive Nancarrow. 1998. Impulse Purchasing : A Qualitative Exploration Of The Phenomenon. Qualitative Market Research : An International Journal. Pp 99-114.

Berman, Barry and Joel R. Evans. 2001, Retail Management A Strategic Approach Eighth Edition. Macmillan. New York..

-------------.. 2004, Retail Management A Strategic Approach Ninth Edition. Macmillan. New York..

Bitner, Mary Jo, Booms, Bernard H Tetrault, Mary Stanfield, 1990, Evaluating Service Encounters:The Effects of Physical Surrounding and Employee Responses. Journal of Marketing, 54 (April): 69-82.

Baumeister, Roy F. 2002. Yielding to Temptation: Self-Control Failure, Impulsive behavior. Journal of consumer Research 28(March): 670-676.

Bellenger, Danny N., Dan H. Robertson, and Elizabeth C. Hirschman. 1978. Impulse Buying Varies by Product. Journal of Advertising Research. 18(6): 15-18

Churchill. Gilbert A. Jr. 2005. Marketing Research Methodological Foundations. Thomson. America.

Clarke, lan. 2000. Retail Power, Competition, and Local Consumer Choice in The UK Grocery Sector. Europen Journal of Marketing. United Kingdom.

Cohen, Louis. Lawrence Manion, Keith Morrison. 2007. Research Method in Education Sixth Edition. Taylor and Francis Group. London and New York.

Cole, Catherine A. and Gaeth, G.J., 1990, Cognitive and Age-Related Differences in the Ability to Use Nutritional Information in a Complex Environment. Journal of Marketing Research, 27 (May): 175-184.

Coley, Amanda, Brigitte Burgess. 2003. Gender differences in cognitive and affective impulse buying. Journal of Fashion Marketing and Management 7(3): 282295.

Dawson, S., Bloch, P.H., and Ridgway, N.M., 1990, Shopping Motive, Emotional States, and Retail Outcome. Journal of Retailing, 66(Winter): 408-427.
Donovan, Roben. John R. Rossiter, 1982, Store Atmosphere : An Environment Psychology Approach. Journal of Retailing, 58 (Spring): 34-57.

Donovan, Roben, John R. Rossiter, Marcoolyn, G., and Nesdale, A., 1994, Store Atmosphere and Purchasing Behavior. Journal of Retailing, 70 (3): 283-294.

Dunne. Patrick M. and Robert F. Lusch. 2005. Retailing Fifth Edition. South Western Thomson. Ohio.

Eroglu, Sevgin. Karen A. Machleit, 1990, An Empirical Study of Retailing Crowding : Antecedent and Consequences. Journal of Retailing, 66 (Summer): 201-221. Gardner, M.P., 1985, Mood States and Consumer Behavior: Critical Review. Journal of Consumer Research, 12 (December): 281-300.

Evans, Martin. Ahmad Jamal, Gordon Foxall. 2006. Consumer Behaviour. John Wiley \& Son, Ltd. England.

Gutierrez. Ben Paul. B. 2004. Determinants of Planned and Impulse Buying: The Case of the Philippines. Asia Pacific Management

Harun Al Rasyid. 1994. Statistika Sosial. Program Pasca Sarjana Universitas Padjajaran. Bandung.

Hatane Semuel. 2005. Respons Lingkungan Berbelanja Sebagai Stimulus Pembelian Tidak Terencana pada Toko Serba Ada (Toserba) (studi Kasus Carrefour Surabaya). Jurnal Manajemen dan Kewirausahan. Surabaya

--onow. Dampak Respon Emosi Terhadap Kecenderungan Perilaku Pembelian Impulsif Konsumen Online dengan Sumberdaya yang Dikeluakan dan Orientasi Belanja Sebagai Variabel Mediasi Jurnal Manajemen dan Kewirausahan. Surabaya

Hausman, Angela. 2000. A Multi-Method Investigation of Consumer Motivations in Impulse Buying Behavior. Journal of Consumer Marketing. Vol 17, pp 403-419.

Hernant. Mikael. 2004. Store Profit Performance In Food Retailing. Department of Industrial Management. Sweden

Hirschman and Holbrook's. 1982. The Consumer and the Shopping Experience. . Journal of Retailing, Amerika. 
Holbrook, Morris B., 1986, Emotion in the Consumption Experience: Toward a New Model of the Human Consumer, In Consumer Self Regulation in a Retail Environment. Barry J. Babin and William R. Darden. Journal of Retailing, 71: 4770.

http

//www.Indef.or.id/xpload/upload/pubs/exum hypermarket, 2010

http

//www.indef.or.id/xpload/upload/pubs/exum hypermarket, 2010

Huelsman. T.J. Nemarick, R.C. Jr and Munz.D.C. 1998. Scales to Measure Four Dimensions of Dispositional Mood : Positive Energy, Tiredness, Negatif Activation, and Relaxation. Education and Psycological Measurement. Vol 59. pp 804-19.

lyer, Easwar S., 1989, Unplanned Purchasing: Knowledge of Shopping Environment and Time Pressure. Journal of Retailing, 65 (Spring): 40-57.

Kotler, Philip. Gary Armstrong. 2006. Principles of Marketing . Pearson Prentice Hall. America

Kotler, Philip. Kevin Lane Keller. 2009. Marketing Management. Prentice Hall International, Northwestern University, New Jersey.

Millan, Elena S. Elizabeth Howard, 2007. Shopping for pleasure? Shopping Experiences of Hungarian Consumers. Oxford.United Kingdom.

Moh. Nasir 1999. Metode Penelitian. Ghalia Indonesia. Jakarta

Moore, Marguerite. 2002. Retail Performance in U.S. Apparel Supply Chains : Operational Efficiency, Marketing Effectiveness and Innovation. NC. State University. Columbia Amerika

Scherhorn, Gerhard, Lucia A. Reisch, Gerhard Raab. 1990. Addictive Buying inWest Germany: An Empirical Study. Journal of Consumer Policy

Nurudin Abdullah. 2003. Arah Bisnis dan Politik Pasca IMF. Bisnis Indonesia. Jakarta.

Park, Eun Joo. Eun Young Kim. Judith Cardona Forney. 2005. A Structural Model of Fashion-Oriented Impulse Buying Behavior. Journal of Fashion Marketing. Vol. 10, pp 433-446
Pemerintah Kota Bandung 2009. Bandung Dalam Angka. Badan Pengolahan Statistik. Propinsi Jawa Barat

Prasad, V.K., 1975, Unplanned Buying in Two

Retail Settings in Consumer

Behavior: Concept and Applications. 4th ed. Loudon, D.L., and Bitta. A.J.D. New York: McGraw-Hill, Inc.

Shoham, Aviv. Maja Makovec Brecic. 2003. Compulsive Buying Behavior. Journal of Consumer Marketing. Israel. Slovenia.

Sidney Siegel. 1956. Nonparametric Statistic for the Behavioral Sciences. Mc Graw-Hill. Kogakusha, LTD. Japan.

Silvera. David.H. Anne M Lavacl, Fredric Kropp. 2008. Impulse Buying: The Role of Affect, Social Influence, and Subjective Wellbeing. Journal of Consumer Marketing.

Sudjana. 2003. Statistika Untuk Ekonomi dan Niaga. Penerbit Tarsito. Bandung

Trang T.M. Nguyen, Tho D. Nguyen, Nigel J. Barrett. 2006. Hedonic Shopping Motivations, Supermarket Attributes, and Shopper Attributes and Shopper Loyalty in Trantional Markets Evidence from Vietnam. Australia

Tremblay, Amelie J. 2005. Impulse Buying Behavior : Impulse Buying Behavior Among College Student In The Borderlands. The University of Texas at EIPaso. USA.

Verplanken, Bas, Astrid Herabadi, Perry, J.A. dan David H. Silvera, 2005. Consumer Style and Health : The Role of Impulsive buying in Unhealty Eating. Psychology and Health. Vol . 20. pp.429-41.

Yadi Budhisetiawan. 2007. Konsumen Indonesia Sangat Sembrono. Marketing. Jakarta

Yilmaz, Veysel, Cengiz Aktas, H. Eray Celik. 2007. Development of a Scale for Measuring Consumer Behavior in Store Choice. Sosyal Bilimer Dergisi Journal. pp 171-184.

Yongki Susilo. 2007. Mencoba yang Serba Instan. Marketing. Jakarta. 